\title{
The Effects of Childhood Trauma on College Completion
}

\author{
Natalie Lecy ${ }^{1}$ (D) $\cdot$ Philip Osteen ${ }^{1}$ (D) \\ Received: 25 August 2020 / Accepted: 26 January 2022 / Published online: 9 February 2022 \\ (c) The Author(s) 2022
}

\begin{abstract}
This study uses the National Longitudinal Study of Adolescent to Adult Health to examine the effect of childhood trauma experiences on college graduation rates. A longitudinal mediation path analysis with a binary logistic regression is performed using trauma as a mediator between race, gender, first-generation status and college completion. The analysis reveals that being female and a continuing-generation student are both associated with greater likelihood of graduating college and that trauma mediates the relationship between race, gender, first-generation status and college completion. The authors explore the implications for these findings for policy, practice, and future research.
\end{abstract}

Keywords First-generation student · Trauma - Childhood adversities · College completion · Path analysis $\cdot$ Mediation model

\section{Introduction}

Earning a college degree remains one of the most reliable paths to economic, health, and social stability (Marmot \& Wilkinson, 2006; Sing-Manoux et al., 2010; Steptoe et al., 2011; U.S. Department of Education, 2018; World Health Organization, 2003). Despite increasing college enrollment rates in the United States, the social-class achievement gap has actually widened (Page et al., 2019; Stephens et al., 2014). First-generation students are distinctly disadvantaged while attempting to access and navigate the system of higher education (Stephens et al., 2014). Given the disproportionate graduation rates of first-generation students, further research is warranted in exploring the factors which contribute to this phenomenon; including the effects of childhood trauma.

Incipient research continually unveils the expansive net trauma casts on later functioning in life (Metzler et al., 2016; Shonkoff \& Garner, 2012). Experiencing childhood trauma correlates with diminished social, emotional, and economic stability into adulthood (Metzler et al., 2016; Sansone et al., 2012; Zielinski, 2009). Despite the budding focus on the effects of childhood trauma on socioemotional outcomes in adults, there is a vast gap in knowledge on the role childhood trauma plays on college achievement rates. This study

Natalie Lecy

natalie.lecy@gmail.com

1 University of Utah, College of Social Work, Salt Lake City, USA 
aims to explore the effect of childhood trauma experiences on later college completion rates among first-generation status, gender, and race.

\section{First-Generation Students and Higher Education}

First-generation students are defined as students without a parent having a college degree, versus continuing-generation students who have at least one parent with a college degree (Stephens et al., 2014). First-generation students comprise between two-fifths and threefifths of all college students (Cataldi et al., 2018; Skomsvold, 2015). First-generation students are more likely to come from lower-socioeconomic households and are more likely to be a racial minority than their continuing-generation counterparts (Horn \& Nunez, 2000; Jack, 2019; Sandoz et al., 2017). These students can face a plethora of obstacles while attempting to navigate higher education. They are more likely to be working part- or fulltime jobs, be enrolled in less credits, feel unwelcome on college campuses, and struggle to create connections with both faculty and their continuing-generation peers (Beegle, 2003; Sandoz et al., 2017; Tate et al., 2015; Wilson \& Gibson, 2011; Wilson et al., 2012).

Obtaining a college degree increases positive outcomes in nearly every facet of life including economic stability, occupational stability, physical health, and mental health (Tate et al., 2015). In regards to health, the benefits of a college degree are vast. Health disparities are wide for college graduates compared to high school graduates; those without college degrees having increased risk for heart disease, diabetes, stroke, cancer, and increased infant mortality rates (World Health Organization, 2003; Zimmerman et al., 2015). Average life expectancy is increased by nine years for college graduates compared to high school graduates (Zimmerman et al., 2015).

Not surprisingly, income and education level are highly correlated (Sandoz et al., 2017). The median income for high school graduates is $\$ 31,800$, compared to $\$ 50,000$ for college graduates and $\$ 64,000$ for those with graduate degrees (U.S. Department of Education, 2018). Obtaining a college degree improves wages and increases access to careers which support higher quality of life with great access to health insurance, increased benefits such as retirement plans, and friendlier work environments (Bloom, 2009). Considering the myriad of health, economic, and social benefits a higher education provides, it is important that students from all backgrounds have equal access and chances of graduating. Unfortunately, first-generation students remain disadvantaged while striving towards the great equalizer of a college degree (Jack, 2019).

\section{Race and Higher Education}

White privilege provides pervasive advantages throughout American culture including our systems of higher education (Diangelo, 2018; Fischer, 2010; Jack, 2019). Racial disparities in higher education are evident by viewing the lower rates at which students of color apply, enroll, and graduate from college (Jones \& Howard, 2020; NCES, 2019). Black, Hispanic, and Indigenous students may experience increased barriers while attending college and are at greater risk for dropping out compared to their White counterparts (Fischer, 2010; NCES, 2019). Achievement gaps for students of color, especially Black students, are worsened when attending predominately white institutions (Beasely et al., 2016). Stereotype threat, social life satisfaction, and campus racial climates have been identified as contributors toward racial disparities in higher education (Fischer, 2010). 
In order to address systemic inequalities embedded in education, it would be fruitful to uncover additional contributing factors to their college completion rates. According to the CDC (2019), people of color are more likely to experience adverse childhood experiences at higher rates than their White counterparts. This raises the question on whether childhood trauma could contribute to college graduation rates by race.

\section{Gender and Higher Education}

Women increasingly enroll, attend, and graduate from college at higher rates than their male counterparts (NCES, 2013). Roughly, they comprise $60 \%$ of college students across the United States (NCES, 2013) and exceed this proportion among Black and American Indian students (Conger \& Dickson, 2017; NCES, 2013). Women tend to have higher grade point averages during high school and are more responsive to supportive services such as financial aid, case management, and mentoring (Conger \& Dickson, 2017). The growing gender imbalance leaves academic institutions in a unique position to determine how to better support their male students. Female representation in academic settings have been steadily growing since the 1970 s (Conger \& Dickson, 2017) but the shift to explicitly creating male preference during college recruitment and retention is nuanced. In an attempt to better understand the dwindling rates of college completion among males, it would be helpful to understand what qualities or experiences contribute to their success or failure. Pertinent to this discussion is unveiling the role of childhood adversities on college graduation rates by gender.

\section{Childhood Trauma}

Emerging research is illuminating the ruminating effects of experiencing childhood trauma on outcomes well into adulthood. This research reveals a negative impact on health, social, mental health, and employment outcomes (Metzler et al., 2016; Sansone et al., 2012; Zielinski, 2009). Surprisingly, little research on childhood trauma and its effect on higher education outcomes exists. Given the alarming rates children in the United States are exposed to trauma, it appears an essential area to explore.

The Centers for Disease Control and Prevention estimate that two out of three U.S. children experience at least one potentially traumatic event prior to their 18th birthday with approximately a quarter of those children experiencing two or more potentially traumatic events prior to the age of 18 (CDC, 2019). Experiencing trauma during childhood has a titanic impact on one's later ability to live a healthy, fulfilling adult life. Exposure to childhood trauma links to poorer physical health, poorer mental health, and greater risky behaviors in later life (CDC, 2019; Metzler et al., 2016).

The landmark study of Adverse Childhood Experiences (ACEs), authored by Felitti et al. (1998) and carried out by the Centers for Disease Control and Kaiser Permanente, created awareness around the prevalence of adverse childhood experiences while also shedding a light on the lifelong toll of childhood trauma (CDC, 2019). Since the Felitti et al. (1998) study revealing the complexity of the long-term health impacts stemming from childhood trauma, research in this area continues to emerge. Through this budding research we are at the threshold of understanding the lingering presence of childhood trauma pervasive in multiple domains of adult life. Areas influenced by childhood trauma include attaining a high school degree, employability, earnings, health outcomes, and interpersonal relationships (Metzler et al., 2016). 


\section{Trauma and Health Outcomes}

The impact of multiple childhood traumas is staggering. The exponential negative impact on long-term health outcomes is known as the dose-response relationship (Flaherty et al., 2013; Metzler et al., 2016). For example, those who experience exposure to four or more different types of trauma have a 12-fold risk increase for depression, suicide attempts, and substance use disorders compared to those without such exposure (Felitti et al., 1998). Childhood exposure to multiple traumas also increases a person's risk for sexually transmitted diseases, smoking, obesity, heart disease, cancer, liver disease, skeletal fractures, involvement in abusive relationships, and premature mortality by 19 years of age (Brown et al., 2009; Felitti et al., 1998; Gilbert et al., 2010).

\section{Trauma's Impact on the Brain}

In addition to illuminating the impact of ACEs on health outcomes, research connects the impact early trauma has on brain development (Brown et al., 2009; Felitti et al., 1998; Gilbert et al., 2010; Shonkoff \& Garner, 2012). Early childhood traumas and exposure to chronic stress impact how the brain develops, often blocking the development of neuropathways from the limbic system to the prefrontal cortex (Babcock, 2014; Shonkoff \& Garner, 2012). The inability to form neuropathways to the prefrontal cortex impacts a range of functions, including planning, task execution, memory, attention span, the ability to learn new skills, and the ability to anticipate events (Shonkoff \& Garner, 2012; Shonkoff et al., 2009). Diminished executive functioning skills affect one's ability to function in all areas of life, which can include impairment in interpersonal relationships, parenting, career stability, educational attainment, and financial planning (Babcock, 2014).

\section{Socioeconomic Outcomes}

The ability to obtain and retain employment correlates to childhood trauma exposure (Sansone et al., 2012). Adults with childhood trauma experiences are twice as likely to be unemployed compared to adults without childhood trauma (Metzler et al., 2016; Zielinski, 2009). Experiencing childhood trauma puts individuals at a higher risk for having economic instability as an adult (Zielinski, 2009). This includes a greater risk of being in households in which other adults are likely to lose their jobs (Zielinski, 2009). Experiencing childhood trauma also increases one's later risk as an adult to live below the poverty line and to be without health insurance (Zielinski, 2009). Since these studies are correlational, it is difficult to pinpoint the cause of economic instability. However, given that childhood trauma experiences impair physical health, mental health, and brain development, it is possible the weight of these factors contributes to the inability to flourish after experiencing multiple childhood traumas. While research consistently demonstrates that childhood trauma negatively impacts adult employability, some speculate that different types of trauma have different effects on individual functioning. For example, some research indicates that experiencing sexual abuse and witnessing violence have a greater negative effect on employability than experiencing physical abuse or neglect as a child (Sansone et al., 2012). Research has not yet isolated the mechanisms behind those connections.

Additionally, children who experience childhood trauma are less likely to graduate from high school than their counterparts (Metzler et al., 2016). Risk of high school 
non-completion correlates with the number of adverse childhood experiences experienced (Metzler et al., 2016). The more categories of childhood trauma experienced, the less likely a person is to have graduated from high school (Metzler et al., 2016). Unfortunately, research on the effects of childhood trauma past high school is limited. Considering the vast effects childhood trauma can have on later outcomes, particularly the executive functioning skills of the brain, there is suggestive evidence that increased childhood trauma could correlate with college completion. Given the tremendous benefits of earning a college degree, it would be helpful to better understand the relationship between childhood trauma and college graduation rates.

\section{Need for Current Research}

Emerging research on the effects of childhood trauma throughout the lifetime is linking trauma with poorer social, emotional, and health outcomes. A connection between childhood trauma and decreased high school graduation rates has been demonstrated (Metzler et al., 2016). Surprisingly, little research has explored the relationship of childhood trauma with outcomes in higher education. Considering the pervasiveness of experiencing childhood adversities, it appears crucial to understand its effects on college degree attainment. Exploring these factors could provide valuable insight into the longer-term obstacles created by childhood trauma.

Gaining information on the effects of childhood trauma on higher education outcomes will provide insight into developing interventions to increase successful college outcomes. If a connection between childhood trauma and college outcomes exist, it could warrant the bridging of trauma informed approaches with environments of higher education. Budding research suggests primary and secondary education environments utilizing traumainformed approaches increase educational outcomes (Herrenkohl et al., 2019; SAMSHA, 2014). If rates of childhood adversities correlate with later college graduation rates by generational status, race, or gender it would contribute to the knowledge base on how to strategically target supports for each subset.

\section{Method}

The present study aims to increase understanding on how experiencing childhood trauma affects college completion. This study aims to answer the questions: (1) Are race, gender, first-generation status, and trauma predictors of college outcomes? (2) Does trauma mediate the relationships between race, gender, first-generation status, and college graduation? To answer these questions, data from the National Longitudinal Study of Adolescent to Adult Health was selected because of its robust information provided from multiple timepoints over the course of fourteen years (more information below).

\section{Study Procedures}

This current study used data from the National Longitudinal Study of Adolescent to Adult Health (AAD Health) which was a nationally representative sample of U.S. youth beginning in the 1994-1995 school year when they were in grades 7-12. The original AAD Health study followed the youth through three more waves including Wave II in 1996, Wave III from 2001-2002, and Wave IV in 2008. The AAD Health study gathered social, 
emotional, health, and economic data from youth, their parents, and their schools. During Wave I, more than 90,000 students in 7th through 12th grades completed in-school surveys. The researchers then selected a random sample of 20,745 from those 90,000 students for in-home interviews. Their primary parent/guardian also completed an in-home interview; school administrative data also was provided. Wave IV ( $n=15,701$, current ages 24-32) consisted of an in-home interview, supplemented by lab tests. All respondents who participated in the original Wave I in-home interviews were eligible for Wave IV in-home interviews. Eighty percent of the eligible participants participated in the final Wave IV in-home interviews. For full details of this longitudinal study, see Harris and Udry (2018).

This dataset is well-suited to answer the research questions outlined above due to the comprehensive nature of the AAD Health dataset including topics related to race, gender, childhood trauma, and college attainment. It also offers advantages over one-time crosssectional surveys since it captured participant data at four separate time points using a mix of surveys, in-home participant interviews, parental interviews, and administrative data.

\section{Participants}

The present study consisted of data collected in Waves I, II, III, and IV. For the present study, the authors limited participants to those who completed each wave of the interviews (Wave I, II, III, and IV) $(\mathrm{n}=5114)$. The sample was further narrowed to include participants who entered four-year colleges. Additionally, only participants who identified as Black or White were included in the final sample. Race was originally assessed as White, Black or African American, American Indian or Native American, Asian or Pacific Islander, or Other (Harris \& Udry, 2018). However, American Indian, Native American, and Asian/Pacific Islander groups did not have sufficient sample sizes for subgroup analysis and were thus removed, bringing the final sample to $n=2917$. Among the participants who entered college, $58.3 \%$ identified as female and $41.7 \%$ as male. Regarding race, $77.6 \%$ of the participants identified as White or Caucasian and $22.4 \%$ indicated their primary identification as Black or African American. First-generation students comprised $49.2 \%$ of the sample and $50.8 \%$ were considered continuing-generation students. In the final interview, the age range was from 24 to 32 years-old $(M=26.9$ years).

\section{Model Variables}

The primary outcome, college completion, was defined by the authors as whether participants graduated from a four-year-college. This information was obtained from participants during Wave IV, in-home interviews. This variable was transformed into a binary variable with the categories defined as did not complete college $=0$; or completed college $=1$.

Childhood trauma was defined as adverse experiences experienced by the participant prior to the age 18. All four waves of AAD Health assessed different trauma experiences, and a total of 17 questions assessed the experiences prior to the age of 18. Questions included assessments of home life such as whether their parents were depressed, mentally ill, or suicidal, whether the participant experienced neglect or abuse. Trauma questions also included experiences that could be external to the home, such as experiencing an assault, or witnessing violence. Sample items include: "Before your 18th birthday, how often did a parent or adult caregiver hit you with a fist, kick you, or throw you down on the floor, into a wall, or down a stairs?", "Have you saw a shooting/stabbing of person?", and "Had a knife/gun pulled on you?". If participants indicated they experienced any dose of the event, 
they were provided a score of one for that response. Responses were summated with higher numbers indicating more trauma experiences. Trauma questions were selected to mirror CDC's (2019) framework around Adverse Childhood Experiences and their Behavioral Risk Factor Surveillance System (CDC BRFSS, 2021). Trauma scores were summed to capture the dose-response relationship demonstrated in previous research, which suggests multiple childhood traumas have an exponential negative impact on long-term outcomes (Flaherty et al., 2013; Metzler et al., 2016).

Gender, generational status, and race are the primary predictors in the model. Gen$d e r$ was a binary category coded as female $=0$ or male $=1$. First-generation was a binary category coded to include participants who had at least one parent graduate from college (continuing-generation $)=0$ versus participants who didn't have a parent who graduated from college (first-generation) $=1$. Race was originally assessed as White, Black or African American, American Indian or Native American, Asian or Pacific Islander, or Other (Harris \& Udry, 2018). Race was recoded into a binary category of White $=0$ or Black $=1$ because all other categories did not have sufficient sample sizes for subgroup analyses.

\section{Analyses}

A longitudinal binary logistic regression mediation path analysis, a subset of structural equation modeling, was performed using Mplus statistical software (version 8.3; Muthén \& Muthén, 1998-2017) using maximum likelihood estimation with robust standard errors (MLR). The model was tested using race, gender, and first-generation status as primary predictors of college completion, and trauma as the mediating variable. The model was just-identified and demonstrated perfect fit to the data.

\section{Results}

The study sample was predominantly female (58.3\%), and White (77.6\%). Generational status was closely distributed with first-generation students representing $49.2 \%$ of the sample and 50.8\% continuing-generation students. Females graduated at higher rates compared to their male counterparts (52.5\% and $46.8 \%$ respectively). In the sample, $44.4 \%$ of Black students completed college, compared to $51.2 \%$ of White students. A starker disproportionality was observed based on generational status, with only $38.0 \%$ of first-generation students graduating compared to $68.0 \%$ of continuing-generation students (Table 1 ).

Trauma experiences ranged from 0 to $9($ Mean $=1.63, S D=1.56)$. On average, males reported $1.67(S D=1.58)$ trauma experiences compared to $1.60(S D=1.55)$ for females.

Table 1 Sample characteristics

\begin{tabular}{lll}
\hline Trait & Sample proportion (\%) & $\begin{array}{l}\text { Graduation } \\
\text { rate }(\%)\end{array}$ \\
\hline Female & 58.3 & 52.5 \\
Male & 41.7 & 46.8 \\
White & 77.6 & 51.2 \\
Black & 32.4 & 44.4 \\
First-Generation & 49.2 & 38.0 \\
Continuing-Generation & 50.8 & 68.0 \\
\hline
\end{tabular}


White students had an average of $1.45(S D=1.49)$ trauma experiences, whereas Black students reported an average of $2.10(S D=1.69)$ trauma experiences. First-generation students reported more trauma experiences $($ Mean $=1.91, S D=1.64)$ than their continuing-generation students $($ Mean $=1.31, S D=1.40)$ (Table 2).

\section{Results for College Completion}

Odds ratios were calculated for direct effects only. To ensure comparisons of direct and indirect effects, our reporting focuses on the linear regression coefficients. For clarity of interpretation regarding odds ratios, negative linear regression coefficients less than one indicate a decreased likelihood of this event happening. Odds ratio of more than one indicates an increased likelihood of this event happening.

\section{Direct Effects}

Whether the student identified as White or Black was not a statistically significant predictor of whether they graduated from college $(b=-0.01, p=0.824)$. Students' gender was a statistically significant predictor of whether the student graduated from college. Male students were less likely to graduate from college than their female counterparts $(b=-0.07$, $\mathrm{p}=0.002$ ). Whether the student was a first-generation student or a continuing-generation student was a statistically significant predictor of whether they would graduate from college. First-generation students were less likely to graduate from college than their continuing-generation counterparts $(b=-0.31, p \leq 0.001)$. Experiencing childhood trauma was a statistically significant predictor of whether they would graduate from college $(b=-0.29$, $\mathrm{p} \leq 0.001$ ). The higher the number of trauma events experienced, the less likely the participant was to graduate from college.

\section{Indirect Effects}

There was a statistically significant indirect effect of race on college completion through childhood trauma experiences corresponding to a full mediation of the relationship between race and college completion $(b=-0.03, p \leq 0.001)$. This indicates that trauma serves as a full mediator between the relationship of race and college completion, suggesting this relationship is expressed by Black students' stronger connection to childhood trauma than White students. There was a statistically significant indirect effect of gender on college graduation through childhood trauma experiences $(b=-0.02, p=0.006)$. Trauma

Table 2 Trauma scores

\begin{tabular}{lll}
\hline Student type & Mean & SD \\
\hline Male & 1.67 & 1.58 \\
Female & 1.60 & 1.55 \\
White & 1.45 & 1.49 \\
Black & 2.10 & 1.69 \\
First-Generation & 1.91 & 1.64 \\
Continuing-Generation & 1.31 & 1.40 \\
\hline
\end{tabular}


serves as a partial mediator between gender and college completion, indicating that a portion of this relationship is manifested in the gender-trauma connection. This means that the reduced likelihood of college completion for males is partially explained by their stronger connection to trauma than females. There was a statistically significant indirect effect of generational status on college graduation through childhood trauma experiences. Trauma serves as a partial mediator to the relationship between generational status and college completion, indicating that a portion of this relationship is manifested in the firstgeneration-trauma connection $(b=-0.02, p=0.001)$. This means the reduced likelihood of college completion for first-generation students is partially explained by their stronger connection to trauma than continuing-generation students (see Table 3; Fig. 1). Direct and indirect effects can be combined to obtain an estimate of the total effect between race, gender, generational status, and childhood trauma experiences and college graduation. Based on the results of the model, the total effect is $20.2 \%\left(\mathrm{R}^{2}=0.202, \mathrm{p}<0.001\right)$.

\section{Discussion}

The findings from the present study suggest experiencing childhood trauma plays a powerful role in college outcomes. The findings suggest that first-generation, male, and Black students experience worse outcomes in higher education as their childhood trauma experiences increase. Considering first-generation, Black, and male students are at increased risk of dropping out of college than their peers (CFFGSS, 2018; NCES, 2019), it is useful to uncover contributing barriers to their success and it appears that childhood trauma may play an important role in their academic trajectories.

First-generation students vary greatly in their demographics and experiences. On average, they tend to graduate at rates $14-15 \%$ lower than their continuing-generation counterparts (DeAngelo et al, 2011; Postsecondary National Policy Institute, 2021). Firstgeneration students are more likely to be older, have dependents, identify as a student of color, work more hours, have less income, and attend school part-time compared to their continuing-generation peers (CFFGSS, 2018; NCES, 2019). Academic literature has long focused on a variety of obstacles contributing to the college trajectory of first-generation students but thus far, the effects of childhood trauma has been underexamined. This study indicates the reduced likelihood of college completion for first-generation students is partially explained by their stronger connection to trauma than continuing-generation students.

Students of color, especially Black students, face substantial obstacles to successfully navigating higher education. Black students face greater barriers in accessing higher education than Whites, including a greater likelihood of living in poverty (Kaiser Foundation, 2017). Once enrolled in college Black students may experience difficulties establishing a sense of belonging, forming social networks, and overcoming racism (Fischer, 2010). Analyzing graduation rates through childhood trauma experiences was especially pertinent for Black students, who did not have statistically significant differences in graduation rates compared to their White counterparts when examining direct effects. However, when using childhood trauma experiences as a mediator, the results indicate trauma serves as a full mediator between the relationship of race and college completion, suggesting this relationship is expressed by Black students' stronger connection to childhood trauma than White students. In order to address the racial disparities pervasive in many systems of higher education, it is essential to uncover potential contributors toward achievement gaps. The full mediation demonstrated in this study between race, trauma experiences, and graduation 
Table 3 Model for predicting college completion

\begin{tabular}{|c|c|c|c|c|c|c|}
\hline & \multirow[t]{2}{*}{$\mathrm{B}$} & \multirow[t]{2}{*}{$\mathrm{SE}_{\mathrm{B}}$} & \multirow[t]{2}{*}{ P-value } & \multicolumn{3}{|l|}{$95 \% \mathrm{CI}$} \\
\hline & & & & Low & High & OR \\
\hline \multicolumn{7}{|l|}{ Direct effects predictor } \\
\hline Race & -0.01 & 0.05 & 0.824 & -0.05 & 0.04 & 0.97 \\
\hline Gender* & -0.07 & 0.02 & 0.002 & -0.12 & -0.03 & 0.74 \\
\hline First-Generation* & -0.31 & 0.02 & $<0.001$ & -0.35 & -0.27 & 0.29 \\
\hline Trauma* & -0.29 & 0.03 & $<0.001$ & -0.34 & -0.24 & 0.55 \\
\hline \multicolumn{7}{|c|}{ Indirect effects predictor } \\
\hline Race* & -0.03 & 0.01 & $<0.001$ & -0.04 & -0.01 & \\
\hline Gender* & -0.02 & 0.01 & 0.006 & -0.03 & -0.01 & \\
\hline First-Generation* & -0.02 & 0.01 & 0.001 & -0.04 & -0.01 & \\
\hline \multicolumn{7}{|l|}{ Total effects predictor } \\
\hline Race & -0.03 & 0.03 & 0.18 & -0.08 & 0.02 & \\
\hline Gender* & -0.09 & 0.03 & $<0.001$ & -0.14 & -0.04 & \\
\hline First-Generation* & -0.33 & 0.02 & $<0.001$ & -0.37 & -0.29 & \\
\hline
\end{tabular}

$* \mathrm{p}<0.05$

rates, indicates a need for the development of policies and interventions addressing the deleterious effects of childhood traumas among Black students on college completion.

Childhood trauma experiences also affect college graduation rates among male students, indicating the reduced likelihood of college completion for males is partially explained by their stronger connection to trauma than females. Overall, female students represent a growing number of the college population with females representing approximately $60 \%$ of college campuses (Jacobs, 2002). This gender imbalance is a growing concern as college graduation rates for males continue to lag (Jacobs, 2002). Research evaluating support services aimed at increasing retention and graduation rates indicate females are more likely to take advantage of both mentoring and financial assistance programs (Angrist et al., 2009). Our findings demonstrating the confounding effect of trauma on male graduation rates, warrants further concern on why these students may be left behind. The development of interventions aimed at addressing the negative outcomes of childhood adversity should consider ways to increase engagement among male students.

\section{Limitations}

The present study utilized data from the National Longitudinal Study of Adolescent to Adult Health to examine the effect of childhood trauma experiences on college graduation rates. This database is extensive and includes a wide breadth of data points from middleschool into adulthood. However, using any secondary dataset creates limitations regarding which research questions can be asked and results should be interpreted within the context of the limitations of the dataset.

One of the limitations is the grouping of the variable "race". The original AAD Health dataset categorized race as White, Black or African American, American Indian or Native American, Asian or Pacific Islander, or Other (Harris \& Udry, 2018). Due to smaller subgroup sizes among American Indians and Asian/Pacific Islanders, they were excluded from 


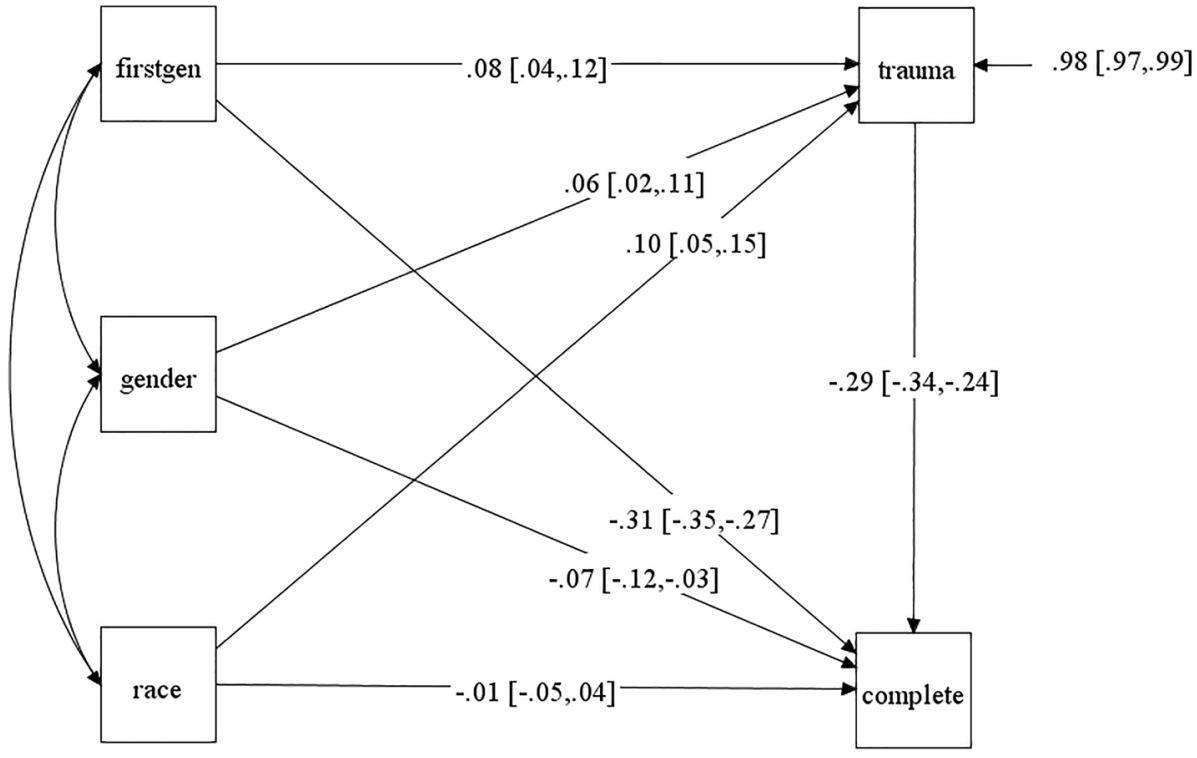

Fig. 1 The Mediation of College Completion (standardized coefficients and 95\% CI's)

the analyses, resulting in a binary variable for race comparing Black versus White students. Postsecondary graduation rates can vary greatly for students in different racial and ethnic groups (NCES, 2019) and it would be beneficial for future research to explore differences experienced across racial groups. However, despite limitations the present study still offered insight into the experiences of Black and White students in regards to the differing role of childhood trauma on their college graduation rates. It was important to explore the relationship between race, childhood trauma, and college graduation rates because people of color often experience childhood adversities at higher rates than Whites (CDC, 2019).

Another consideration to the present study was the ability to capture childhood trauma experiences. AAD Health did have an extensive set of questions throughout the course of the study that captured a variety of childhood trauma experiences. However, the questions were not standardized or based upon any specific measurement tools. Fortunately, many of the questions paralleled those of the more prominent Adverse Childhood Experiences (ACEs) questionnaire with the present study also including some experiences that could happen outside of the family (witnessing or experiencing violence).

\section{Implications}

The findings from this study increase our knowledge base on the effects of gender, race, first-generation status, and childhood trauma on later college degree completion. The present study indicates that first-generation students, male students, and those who experienced increased childhood trauma are at higher risk of not completing college once enrolled. Experiencing childhood trauma increases the risk of dropping out of college for first-generation students, males, and Black students. These findings suggest targeting interventions which better support increased graduation rates among these groups could be fruitful and have a considerable economic payout long-term. If greater rates of first-generation, Black, 
and male students graduated college, their earning potential would increase and they would likely experience better physical, social, and emotional well-being.

Future research should explore whether existing school environments are successfully supporting the retention of these students and which interventions are effectually increasing their retention and graduation rates. In order to target future policy and practice efforts, it would be helpful to better understand the experiences of these student groups and what perceived barriers exist. Further, it would be advantageous to better understand if there are existing academic environments or programs supporting these students to thrive and what mechanisms are increasing graduation rates.

This study was one of the first exploring the effects of childhood trauma on later college completion. Considering the results, more research is merited to explore the relationship between childhood trauma and college completion rates. Germane to this idea is the newly emerging research on the effectiveness of using trauma-informed approaches for primary and secondary academic settings (SAMSHA, 2014). Currently, research on the implementation of trauma-informed approaches targeting college level students appear nonexistent. Considering approximately $66 \%$ of the population experiences at least one traumatic event prior to their 18th birthday (CDC, 2019), utilizing trauma-informed approaches in higher education settings would be useful in supporting the vast majority of students.

A trauma-informed approach is not a program but more of a philosophy encouraging school-wide systemic changes. Trauma-informed approaches could be adapted into campus settings in a variety of ways including trauma specific interventions, classroom adaptations, or more broadly incorporated into organizational culture. Basic tenets of a trauma-informed approach include (1) fostering an environment of safety, (2) being trustworthy and transparent, (3) utilizing peer support, (4) collaborating and working toward mutually agreed upon goals, (5) empowerment, voice, and choice, and (6) consideration of cultural, historical, and gender issues (SAMSHA, 2014). Embracing this framework may seem foreign to academics, however, tenets of trauma-informed care already parallel common frameworks used in education settings such as learner-centered theory. Learner-centered theories have been implemented in education settings with the hopes of fostering conducive mentoring between educators and students (Boyer, 2016; Cornelius-White, 2008). Core components of learner-centered theory emphasize sharing control and choice between educators and students, shifting the focus towards the learner (as opposed to the teacher), and mutual endorsement of learning projects (Cornelius-White, 2008).

This study shed light on the negative effects of childhood trauma on college graduation rates, especially for first-generation, male, and Black students. While considering potential policies and strategies to better support students, it would be beneficial to utilize trauma-informed frameworks which promote safety and authentic learning, encouraging all students to actualize their full potential. Since experiencing childhood adversities are widespread and their effects far-reaching, implementing cultural shifts and multi-pronged approaches in higher education to combat their negative lifelong effects would be advantageous (SAMSHA, 2014). Bearing in mind the multitude of benefits of earning a college degree, investing in strategies which increase college graduation rates for these populations would strengthen the economic fibers of our country. 


\section{Declarations}

Conflict of interest The authors declare they have no conflict of interest.

Open Access This article is licensed under a Creative Commons Attribution 4.0 International License, which permits use, sharing, adaptation, distribution and reproduction in any medium or format, as long as you give appropriate credit to the original author(s) and the source, provide a link to the Creative Commons licence, and indicate if changes were made. The images or other third party material in this article are included in the article's Creative Commons licence, unless indicated otherwise in a credit line to the material. If material is not included in the article's Creative Commons licence and your intended use is not permitted by statutory regulation or exceeds the permitted use, you will need to obtain permission directly from the copyright holder. To view a copy of this licence, visit http://creativecommons.org/licenses/by/4.0/.

\section{References}

Angrist, J., Lang, D., \& Oreopoulos, P. (2009). Incentives and services for college achievement: Evidence from a randomized trial. American Economic Journal: Applied Economics, 1, 1-28.

Babcock, E. (2014). Using brain science to design new pathways out of poverty. Crittenton Women's Union. Retrieved from https://s3.amazonaws.com/empath-website/pdf/Research-UsingBrainScien ceDesignPathwaysPoverty-0114.pdf

Beasley, S. T., Chapman-Hilliard, C., \& McClain, S. (2016). Linking the emancipatory pedagogy of Africana/Black studies with academic identity outcomes among Black students attending PWIs. Africology: the Journal of Pan African Studies, 9, 9-25.

Beegle, D. M. (2003). Overcoming the silence of generational poverty. National Council of Teachers of English, 15, 11-20.

Bloom, L. R. (2009). 'When one person makes it, we all make it": A study of Beyond Welfare, a womencentered community-based organization that helps low-income mothers achieve personal and academic success. International Journal of Qualitative Studies in Education, 22, 485-503. https://doi. org/10.1080/09518390902740597

Boyer, W. (2016). Person-centered therapy: A philosophy to support early childhood education. Early Childhood Education Journal, 44, 343-348.

Brown, D. W., Anda, R. F., Tiemeier, H., Felitti, V. J., Edwards, V. J., Croft, J. B., \& Giles, W. H. (2009). Adverse childhood experiences and the risk of premature mortality. American Journal of Preventive Medicine, 37, 389-396. https://doi.org/10.1016/j.amepre.2009.06.021

Cataldi, E. F., Bennett, C. T., \& Chen, X. (2018). First-generation students: College access, persistence, and postbachelor's outcomes. U.S. Department of Education. Washington, DC: National Center for Education Statistics. Retrieved from https://nces.ed.gov/pubs2018/2018421.pdf

Center for First-Generation Success (CFFGS). (2018). Demographic Characteristics and Postsecondary enrollment: Fact Sheet. Retrieved from https://firstgen.naspa.org/files/dmfile/FactSheet-01.pdf

Center for Disease Control and Prevention. (2019). About the CDC-Kaiser ACE Study. Retrieved from https://www.cdc.gov/violenceprevention/childabuseandneglect/acestudy/about.html

Center for Disease Control and Prevention. (2021). Behavioral Risk Factor Surveillance System. Retrieved from https://www.cdc.gov/brfss/index.html

Conger, D., \& Dickson, L. (2017). Gender imbalance in higher education: Insights for college administrators and researchers. Research in Higher Education, 58(2), 214-230. https://doi.org/10.1007/ s11162-016-9421-3

Cornelius-White, J. H. D. (2008). Reexamination of Rogers' (1959) collection of theories on the personcentered approach. Person-Centered and Experiential Psychotherapies, 7, 201-208.

DeAngelo, L., Franke, R., Hurtado, S., Pryor, J. H., \& Tran, S. (2011). Completing college: Assessing graduation rates at four-year institutions. Higher Education Research Institute.

Diangelo, R. (2018). White fragility: Why it's so hard for white people to talk about racism. Beacon Press.

Felitti, V. J., Anda, R. F., Nordenberg, D., Williamson, D. F., Spitz, A. M., Edwards, V., \& Marks, J. S. (1998). Relationship of childhood abuse and household dysfunction to many of the leading causes of death in adults: The Adverse Childhood Experiences (ACE) Study. American Journal of Preventive Medicine, 14, 245-258. https://doi.org/10.1016/s0749-3797(98)00017-8 
Fischer, M. J. (2010). A longitudinal examination of the role of stereotype threat and racial climate on college outcomes for minorities at elite institutions. Social Psychology of Education, 13, 19-40. https:// doi.org/10.1007/s11218-009-9105-3

Flaherty, E. G., Thompson, R., Dubowitz, H., Harvey, E. M., English, D. J., Proctor, L. J., \& Runyan, D. K. (2013). Adverse childhood experiences and child health in early adolescence. JAMA Pediatrics \& Adolescent Medicine, 160, 1232-1238. https://doi.org/10.1001/jamapediatrics.2013.22

Gilbert, L. K., Breiding, M. J., Merrick, M. T., Thompson, W. W., Ford, D. C., Dhingra, S. S., \& Parks, S. E. (2010). Childhood adversity and adult chronic disease: An update from ten states and the District of Columbia. American Journal of Preventive Medicine, 48, 345-349. https://doi.org/10.1016/j.amepre. 2014.09.006

Harris, K. M., \& Udry, R. J. (2018). National Longitudinal Study of Adolescent to Adult Health (Add Health), 1994-2008 [Public Use]. Ann Arbor, MI: Carolina Population Center, University of North Carolina-Chapel Hill [distributor], Inter-university Consortium for Political and Social Research [distributor], 2018-08-06. 10.3886/ICPSR21600v21

Herrenkohl, T. I., Hong, S., \& Verbrugge, B. (2019). Trauma-informed programs based in schools: Linking concepts to practices and assessing the evidence. American Journal of Community Psychology, 64, 373-388.

Horn, L., \& Nunez, A. (2000). Mapping the road to college: First-generation students' math track, planning strategies, and context of support (NCES Report 00-153). Washington

Jack, A. B. (2019). The privileged poor: How elite colleges are failing disadvantaged students. United States of America: Anthony Abraham Jack. DC: U.S. Department of Education, National Center for Education.

Jacob, B. (2002). Where the boys aren't: Non-cognitive skills, returns to school and the gender gap in higher education. Economics of Education Review, 21, 589-598. https://doi.org/10.1016/S0272-7757(01) 00051-6

Jones, T., \& Nichols, A. H. (2020). Hard truths: why only race-conscious policies can fix racism in higher education. Education Trust. Retrieved from https://files-eric-ed-gov.ezproxy.lib.utah.edu/fulltext/ ED603265.pdf

Kaiser Family Foundation estimates based on the Census Bureau's American Community Survey. (20082017). Poverty rate by race/ethnicity. Retrieved from https://www.kff.org/other/state/-indicator/pover ty-rate-byraceethnicity/?currentTimeframe $=0 \&$ sortModel $=7 \mathrm{~B} \% 22$ colId $\% 22: \% 22$ Location $\% 22, \%$ 22sort $\% 22: \% 22$ asc $\% 22 \% 7 \mathrm{D}$

Marmot, M. G., \& Wilkinson, R. G. (2006). Social determinants of health (2nd ed.). Oxford University Press.

Metzler, M., Merrick, M. T., Klevens, J., Ports, K. A., \& Ford, D. C. (2016). Adverse childhood experiences and life opportunities: Shifting the narrative. Child and Youth Services Review, 72, 141-149.

Muthén, L.K., \& Muthén, B.O. (1998-2017). Mplus User's Guide.

National Center for Education Statistics (NCES). (2013). College standards stiffer for women. Retrieved from http://nces.ed.gov/programs/digest/d14/tables/dt14_303.30asp

National Center for Education Statistics (NCES). (2019). Status and trends in the education of racial and ethnic groups. Retrieved from https://nces.ed.gov/programs/raceindicators/indicator_red.asp

Page, L. C., Kehoe, S. S., Castleman, B. L., \& Sahadewo, G. A. (2019). More than dollars for scholars: The impact of the Dell Scholars Program on college access, persistence, and degree attainment. Journal of Human Resources, 54, 683-725.

Postsecondary National Policy Institute. (2021). Factsheets: First-generation students. Retrieved from https://pnpi.org/first-generation-students/

Sandoz, E. K., Kellum, K. K., \& Wilson, K. (2017). Feasibility and preliminary effectiveness of acceptance and commitment training for academic success of at-risk college students from low income families. Journal of Contextual Behavioral Science, 6, 71-79.

Sansone, R. A., Leung, J. S., \& Wiederman, M. W. (2012). Five forms of childhood trauma: Relationships with employment in adulthood. Child Abuse \& Neglect, 36, 676-679. https://doi.org/10.1016/j.chiabu. 2012.07.007

Shonkoff, J. P., Boyce, W. T., \& McEwen, B. S. (2009). Neuroscience, molecular biology, and the childhood roots of health disparities: Building a new framework for health pro- motion and disease prevention. Journal of the American Medical Association, 301, 2252-2259. https://doi.org/10.1001/jama.2009.754

Shonkoff, J. P., \& Garner, A. S. (2012). The lifelong effects of early childhood adversity and toxic stress. Pediatrics, 129, e232-e246. https://doi.org/10.1542/peds.2011-2663

Sing-Manoux, A., Akbaraly, T. N., Marmot, M., Melchoir, M., Ankri, J., Sabia, S., \& Ferrie, J. E. (2010). Persistent depressive symptoms and cognitive function in late midlife: The Whitehall II study. Journal of Clinical Psychiatry, 71, 1379-1385. https://doi.org/10.4088/JCP.09m05349gry 
Skomsvold, P. (2015). Web Tables-Profile of Undergraduate Students: 2011-12 (NCES 2015-167). U.S. Department of Education. Washington, DC: National Center for Education Statistics. Retrieved from https://nces.ed.gov/pubsearch/pubsinfo.asp?pubid=2015167

Stephens, N. M., Hamedani, M. G., \& Destin, M. (2014). Closing the social-class achievement gap: A difference-education intervention improves first-generation students' academic performance and all students' college transition. Psychological Science, 25(4), 943-953. https://doi.org/10.1177/0956797613 518349

Steptoe, A., Hamer, M., Butcher, L., Lin, J., Brydon, L., Kivimaki, M., \& Eruasalimsky, J. D. (2011). Educational attainment but not measures of current socioeconomic circumstances are associated with leukocyte telomere length in healthy older men and women. Brain, Behavior, and Immunity, 25, 12921298. https://doi.org/10.1016/j.bbi.2011.04.010

Substance Abuse and Mental Health Services Administration. (2014). SAMHSA's Concept of Trauma and Guidance for a Trauma-Informed Approach. HHS Publication No. (SMA) 14-4884. Rockville, MD: Substance Abuse and Mental Health Services Administration.

Tate, K. A., Fouad, N. A., Marks, L. R., Young, G., Guzman, E., \& Williams, E. G. (2015). Underrepresented first-generation, low-income college students' pursuit of a graduate education: Investigating the influence of self-efficacy, coping efficacy, and family influence. Journal of Career Assessment, 23, 427-441.

U.S. Department of Education, National Center for Education Statistics. (2018). The Condition of Education 2018 (NCES 2018-144), Annual earnings of young adults. Retrieved from https://nces.ed.gov/fastfacts/ display.asp?id=77

Wilson, S., \& Gibson, E. (2011). Graduate school learning curve: McNair Scholars' postbaccalaureate transitions. Equity \& Excellence in Education, 44, 153-168.

Wilson, Z. S., Iyengar, S. S., Pang, S. S., Warner, I. M., \& Luces, C. A. (2012). Increasing access for economically disadvantaged students: The NSF/CSEM \& S-STEM Programs at Louisiana State University. Journal of Science Education and Technology, 21, 581-587.

World Health Organization. (2003). Social determinants of health: The solid facts. Retrieved from http:// www.eruo.who.int/en/what-we-publish/abstracts/social-determinants-of-health.-the-solid-facts

Zielinski, D. S. (2009). Child abuse and neglect and adult socioeconomic well-being. Child Abuse \& Neglect, 33, 666-678. https://doi.org/10.1016/j.chiabu.2009.09.001

Zimmerman, E. B., Woolf, S. H., \& Haley, A. (2015). Understanding the relationship between education and health: A review of the evidence and an examination of community perspectives. Agency for Healthcare Research and Quality, Rockville, MD. Retrieved from http:/www.ahrq.gov/professionals/ education/curriculum-tools/population-health/zimmerman.html

Publisher's Note Springer Nature remains neutral with regard to jurisdictional claims in published maps and institutional affiliations. 